\title{
Study of the Efficacy and Safety of Topical Ivermectin + Iota- Carrageenan in the Prophylaxis against COVID-19 in Health Personnel
}

\author{
Carvallo Héctor ${ }^{1}$, Hirsch Roberto $^{2 *}$, Contreras Veronica ${ }^{3}$ \\ ${ }^{1}$ Professor of Internal Medicine, Universities of Buenos Aires and U.A.I., Argentina \\ ${ }^{2}$ Professor of Infectology, University of Buenos Aires, Argentina \\ ${ }^{3}$ In Charge of Biosafety, Eurnekian Public Hospital, Argentina
}

\begin{abstract}
The severe acute respiratory syndrome-coronavirus-2 pandemic has had devastating health and socio-economic implications worldwide. Epidemiologic data indicate that SARS-CoV2 is spread by respiratory droplets and contact. The lack of acquired human immunity to the virus and the absence of a vaccine, has meant that current management strategies aimed at virus containment through mask wearing, social distancing and enforced lockdowns. Although the World Health Organization recommends 1,5 meters distancing to minimize transmission, recent studies have demonstrated high stability in aerosols and transmission distances up to 10 meters from emission sources .

Health care workers are at particular risk from SARS-CoV-2. At present, no reliable prophylactic therapy exists to minimize their risk of acquiring SARS-CoV-2, and so they rely solely upon hand hygiene and the wearing of appropriate personal protective equipment (PPE), which is often in limited supply. Several studies have shown that the salivary gland and tongue express the ACE2 receptor, suggesting that the oral cavity is a perfect host for the invasion of COVID. Theoretically, agents that can inhibit viral adhesion and replication within the primary sites of viral entry (the nasal and oral cavity), may have a role in preventing SARS-CoV-2 transmission. Use of these agents prophylactically, would be especially beneficial in health care workers, particularly given the delay in results from viral RNA detection diagnostic test and the fact that many infected patients may have mild or no symptoms of the virus in the early stages. Two possible substances have been identified as candidate prophylactic agents in the fight against SARS-CoV-2. Carrageenans are naturally occurring extracts from the Rhodophyceas seaweed. Recently, the viricidal capacity of carrageenan has been reported, through inhibition of viral- host cell adhesion and early replication. Iota-carrageenan demonstrates potent antiviral activity in vitro, reducing rhinovirus, herpes simplex virus and the Japanese encephalitis virus reproduction and their cytopathic effects. Similarly, ivermectin has also been shown to posess antiviral activity against a whole host of RNA viruses (Zika, dengue, yellow fever, human immunodeficiency virus type 1). Thus, the combination of both products can provide an extra protection for those at risk of contagion.
\end{abstract}

Keywords: COVID-19, Ivermectin, SARS-CoV-2.

\section{Introduction}

The severe acute respiratory syndrome-coronavirus-2 (SARSCoV-2) pandemic has had devastating health and socioeconomic implications worldwide. Epidemiologic data indicate that SARS-CoV is spread by respiratory droplets and contact [1].
Corresponding Author: Hirsch Roberto, University of Buenos Aires, Argentina Received date: November 09, 2020; Accepted date: November 16, 2020; Published date: November 17, 2020.

DOI: https://doi.org/10.31546/2633-8653.1007 
Binding of the virus to ACE-2 receptors expressed in the respiratory tract and eyes, is the proposed mechanisms of entry of SARS-CoV-2 into human cells. The lack of acquired human immunity to the virus and the absence of a vaccine, has meant that current management strategies aimed at virus containment through mask wearing, social distancing and enforced lockdowns. Although the World Health Organization recommends 1-5-2 meter distancing to minimize transmission, recent studies have demonstrated high stability in aerosols and transmission distances up to 10 meters from emission sources. Health care workers are at particular risk from SARS-CoV-2. Their close proximity to infected patients during examination and procedural tasks renders them at increased risk of exposure to higher viral loads, which may result in more prolonged and severe disease. At present, no reliable prophylactic therapy exists to minimize their risk of acquiring SARS-CoV-2, and so they rely solely upon hand hygiene and the wearing of appropriate personal protective equipment (PPE), which is often in limited supply [2-4,10].

The source of contagion is related to Pflügge drops, droplets and aerosols. All of them are different sizes of salivary compounds. Whole saliva is a biomix containing crevicular fluid, desquamated oral epithelial cells, and microorganisms. Around $99 \%$ of saliva is water and the remaining $1 \%$ contains a large group of components for the purpose of digesting, tasting, buffering, balancing remineralization and antimicrobials.Several studies have shown that the salivary gland and tongue express the ACE2 receptor, suggesting that the oral cavity is a perfect host for the invasion of COVID.

For COVID-19, the salivary gland could be an important room, generating infectious saliva on a sustained basis.It has been observed that low levels of COVID-19 RNA could still be excreted in saliva even after clinical recovery. Additionally, about half of the patients reported symptoms of dry mouth and dysgeusia.These symptoms probably stem from dysfunction of the tongue expressing ACE2 and furin, and the expression of the salivary gland ACE2, apart from SARS COV 2 direct neurotropism [19-21].

Theoretically, agents that can inhibit viral adhesion and replication within the primary sites of viral entry (the nasal and oral cavity), may have a role in preventing SARS-CoV-2 transmission. Use of these agents prophylactically, would be especially beneficial in health care workers, particularly given the delay in results from viral RNAdetection diagnostic test and the fact that many infected patients may have mild or no symptoms of the virus in the early stages. Two possible substances have been identified as candidate prophylactic agents in the fight against SARS-CoV-2 [8].
Carrageenans are naturally occurring extracts from the Rhodophyceas seaweed. They are commonly used as thickening agents in the food industry with FDA approval for this indication. Recently, the viricidal capacity of carrageenan has been reported, through inhibition of viral- host cell adhesion and early replication. Iota-carrageenan demonstrates potent antiviral activity in vitro, reducing rhinovirus, herpes simplex virus and the Japanese encephalitis virus reproduction and their cytopathic effects. This effect is supposed to be mediated by the interaction of sulfated polysaccharides with positively charged domains on the glycoprotein envelope involved in binding with proteinglycans on the surface of the host cell [6].

Similarly, ivermectin has also been shown to posess antiviral activity against a whole host of RNA viruses (Zika, dengue, yellow fever, human immunodeficiency virus type 1). Recent in vitro studies have also shown effect on Covid-19 [7].

Ivermectin mechanisms of action are both extracellular and intracellular. Outside the host cell, it provokes ionophores along the virus lipoprotein nocleocapside, thus allowing the entrance of oxhidril compounds which damage the virus structure. Despite this, if the virus does enter cytosol, ivermectin blocks its transportation to the cell nucleus, by keeping the virus from using importins alpha and beta1 to do so. In vitro sutdies, ivermectin proved to reduce viral load 5000 times in laboratory specimens $[5,9,11]$.

\section{Materials and Method}

This pilot and muti-center clinical trial assesses whether a combination of topical nasal carageenan and oral ivermectin can reduce SARS-CoV-2 infection in Health Care Workers when administered prophylactically. The safety and efficacy of this combination therapy will be discussed and compared to the use of standard PPE alone [14].

\section{Methods}

\section{Pilot Study (clinicaltrials.gov NCT 04425850)}

Ethics board approval was attained prior to the commencement of this study and all participants provided informed consent prior to study enrollment. Asymptomatic health care workers employed at the Alberto Antranik Eurnekian Hospital, Argentina and involved in the care of and contact of Covid-19 patients were recruited. 
All HCW's were healthy with no Covid-19 symptoms and negative swabs for the virus immediately prior to enrollment in the study. Exclusion criteria included: Children < 18 years old, pregnancy, active breast feeding, concurrent autoimmune or chronic disease, immunosuppression, active infectious diseases and a history of previous infection with SARSCoV-2 confirmed by PCR or rapid test. Participants received active treatment with a combination of carrageenan and ivermectin and were compared to a cohort of healthy volunteers who simply adhered to the use of appropriate personal protective equipment.

Following informed consent eligible patients underwent standardized symptom questionnaire and physical examination. Those with negative CoVid-19 (PCR or rapid test) were then recruited for preventive measures with active combination treatment (IVERCAR) arm in addition to their wearing of personal protective equipment (PPE). Acohort of healthy, age Covid-19 negative health care workers using standard PPE alone was used as a comparative arm, in a prospective, observational, not randomized trial. This group was matched for age, demographics, past medical history, work environment including hours worked and possible exposure to CoVid 19 positive patients within the hospital [16-18].

Combination therapy (IVECAR) consisted of 1 spray of topical Carrageenan (Cert. No. 57,232, ANMAT (National Administration for Drugs, Food and Medical Technology) 100 $\mathrm{ml}, 0.9 \mathrm{~g}$ of sodium chloride and $0.17 \mathrm{~g}$ of carrageenan) into each nostril and four sprays of topical Carageenan into the oral cavity, followed 5 minutes later by 1 drop of ivermectin (Cert. $\mathrm{N}^{\circ} 58.382$, ANMAT $100 \mathrm{ml}$ Ivermectin drops $(0.6 \mathrm{mg} / \mathrm{ml})$ to the tongue 5 minutes later. This dosage schedule was repeated 5 times a day (every 4 hours) for 14 days with food and liquids avoided 1 hour before and after treatment [12-15].

Patients in the PPE group and IVECAR groups were evaluated at 7 and 14 days completing symptom questionnaires ( including the reporting of any adverse effects from the treatment), physical examinations and CoVid-19 testing of nasopharyngeal secretions (PCR or rapid test) at each time point. Both groups continued to adhere to standard PPEs and were evaluated at $7,14,21$ and 28 days from the commencement of the study. Infection rates were reported for each group, with 11 contagions among those not treated, and no contagions in the treated group [22-26].

Outcomes assessed for each of the two groups included:

- Incidence of appearance of symptoms related to CoVid-19 infection

- Incidence of detection of CoVid-19 by PCR

- Incidence of reported adverse events

\section{Statistical Analysis \\ Results \\ Pilot Study Demographics}

A total of 229 health personnel were recruited for this study; 98 within the control (PPE alone) group and 131 received IVECAR treatment in addition to their wearing of PPE.

Table 1: summarizes the demographics of each group.

\begin{tabular}{|c|c|c|}
\hline Health Personnel & With IVER.CAR & Without IVER.CAR \\
\hline Female Nurses $<40$ years & 20 & 9 \\
\hline Female Nurses $>40$ to 55 years & 5 & 5 \\
\hline Male Nurses $<40$ years & 12 & 9 \\
\hline Male Nurses $>40$ to 55 years & 6 & 5 \\
\hline E.R. Female Doctors $<40$ years & 11 & 7 \\
\hline E.R. Female Doctors $>40$ to 60 years & 4 & 6 \\
\hline E.R. Male Doctors $<40$ years & 10 & 6 \\
\hline E.R. Male Doctors $>40$ to 60 years & 3 & 6 \\
\hline ICU Female Doctors $<40$ years & 3 & 5 \\
\hline ICU Female Doctors $>40$ to 60 years & 1 & 1 \\
\hline ICU Male Doctors < 40 years & 2 & 6 \\
\hline ICU Male Doctors > 40 to 60 years & 2 & 3 \\
\hline Female Radiologists $<40$ years & 5 & 6 \\
\hline Female Radiologists $>40$ to 55 years & 1 & - \\
\hline Male Radiologists $<40$ years & 4 & 5 \\
\hline Male Radiologists $>40$ to 55 years & 3 & 1 \\
\hline Female Cleaning Staff $<40$ years & 8 & 3 \\
\hline Female Cleaning Staff $>40$ to 60 years & 2 & 6 \\
\hline Male Cleaning Staff $<40$ years & 6 & 3 \\
\hline Male Cleaning Staff $>40$ to 60 years & 4 & 3 \\
\hline Female Anesthesiologists & 6 & 2 \\
\hline Male Anesthesiologists & 1 & - \\
\hline Male Hemotherapeutic Staff & 5 & 1 \\
\hline Female Lab. Personnel $<40$ years & 6 & 1 \\
\hline Male Lab. Personnel $<40$ years & 2 & - \\
\hline Total & 131 & 98 \\
\hline
\end{tabular}

As far as ethnicity is concerned, all the persons included have latin origin.

\section{Statistical Analysis}

COVID-19 transmission rates in both arms were compared by chi squared test. Transmission rate in the treated group is statistically significantly lower in the treated group $(\mathrm{p}<0.0001)$. Relative risk reduction was calculated based on literature, and found to be $15 \%$ for the add-on nasal and buccal iota carrageenan + ivermectin nasal + buccal preventive treatment.

\section{Infection rates}

None of the health personnel treated with IVERCAR tested positive for CoVid19 during the 14 day treatment period. Furthermore none returned positive swabs in the 3 weeks'post completion of their initial treatment. Eleven health personnel $(11.1 \%)$ in the comparator PPE group yielded positive swabs. 
7 of the 11 patients with positive swabs were nurses. 1 Intensivist, 1 anesthesiologist, 1 hemotherapeutic technician and 1 laboratory technician also returned positive swabs. (see Figure 1)

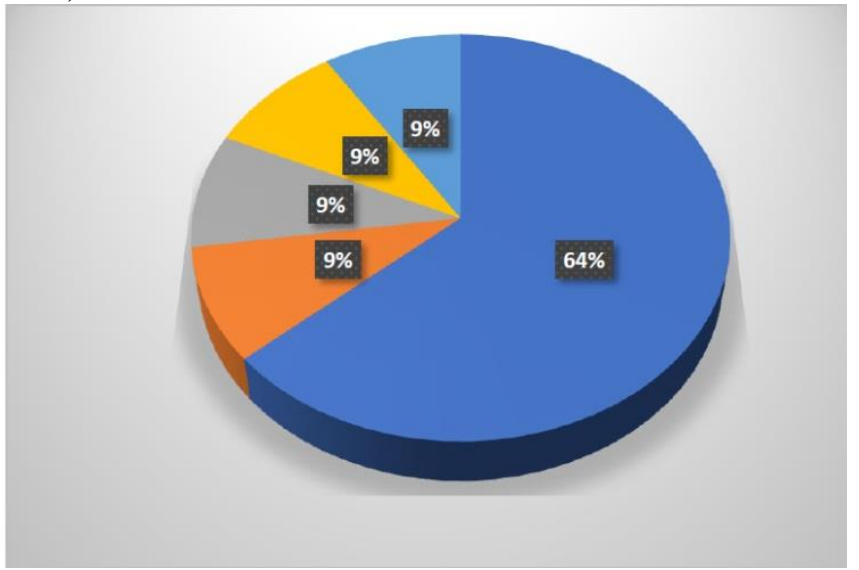

Blue: Nurses; Orange: Anesthetiologist; gray: Lab. Personnel; ocre: ICU Personnel; Light Blue: Hemotherapeutic Pnel.

\section{Further Multicenter Study}

Following the promising results of the initial study (see above), a larger multi-center study was performed with health care personnel recruited from Alberto Antranik Eurnekian Hospital, and 3 other hospitals; Hospital Municipal Angel Marzetti ( Canuelas), Cuenca Alta Hospital (Buenos Aires Province) and Centro Medico Caseros ( C.A.B.A). The study period was from June 12020 - August 1 2020. A modification of the initial protocol was performed for ease of medication delivery. Carageenan application was reduced to $4 \mathrm{x}$ a day at the same total dose, and Ivermectin was administered as once per week dose of $12 \mathrm{mg}$. Each of the 4 centers used the same dosing protocol. Again, two arms were built: those who received the prophilaxis and standard PPEs, and a cohort who only used PPEs.

Both standardized symptom questionnaire and physical examination were repeated. Those with negative CoVid-19 (PCR or rapid test) were then recruited for preventive measures with active combination treatment (IVERCAR) arm in addition to their wearing of personal protective equipment (PPE). A cohort of healthy, age Covid-19 negative health care workers using standard PPE alone was used as a comparative arm, once again in a prospective, observational, not randomized trial. No further demographic details were collected, except for successive swabs during the 60 days' follow-up.

A total of 1,195 health care workers were recruited from 4 major hospitals in Argentina with 730 from Alberto Antranik Eurnekian Hospital, 150 from Hospital Municipal Angel Marzetti, 150 from Cuenca Alta Hospital and 15 from Centro Medico Caseros.
788 participants received IVERCAR and PPEs, while the remaining 407 simply adhered to standard PPEs.

\section{Infection Rates - Pooled Results}

The overall infection rate in health care workers recruited for this study was $20 \%$ with 237 testing positive for CoVid 19 during the 3 month study recruitment. Of those infected, all patients were from the comparator group of using PPE alone. This represented an overall infection rate of $58.2 \%$ ( 237 of 407) in the PPE group.

No patients of the 788 treated with IVERCAR tested positive for CoVid 19 during the study.

\section{Infections Rates - Per Hospital \\ Alberto Antranik Eurnekian Hospital - EZEIZA City:}

Total participating personnel $730 ; 600$ received IVERCAR and 130 used PPE alone. 120 of $13092.3 \%$ personnel in the PPE alone group returned positive CoVid 19 swabs, while 0 of the 600 individuals receiving IVERCAR treatment in addition to PPE tested positive for CoVid-19 in the study period.

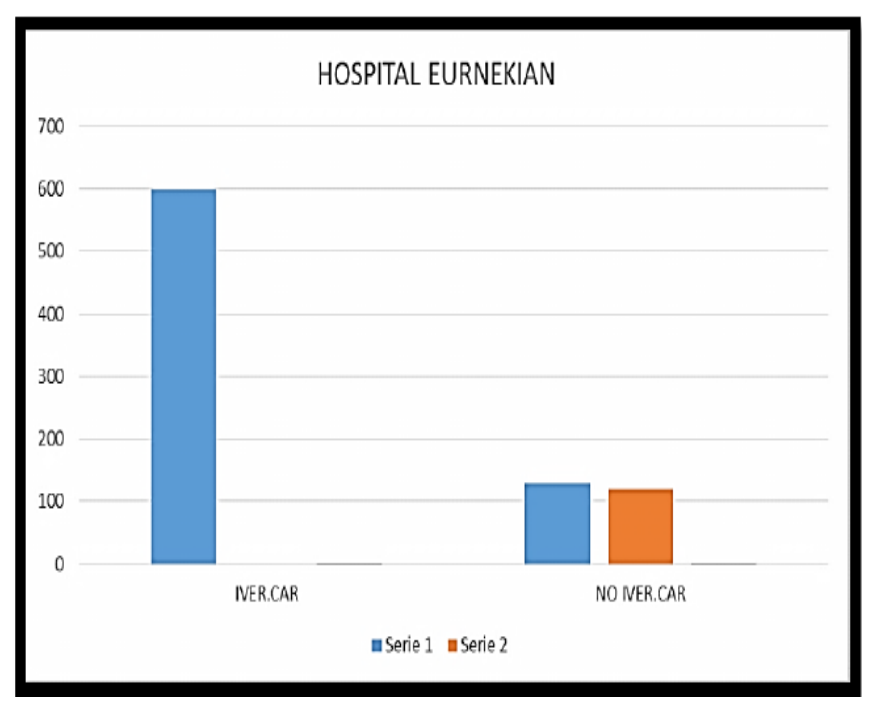

Figure 1: Light Blue: Participant Personnel; Orange: Personnel Infected

\section{Hospital Municipal Ángel Marzetti - CAÑUELAS City:}

Total participating personnel 150; 90 received IVERCAR and 60 used PPE alone. 47 health care personnel $(78.3 \%)$ in the PPE alone group returned positive CoVid 19 swabs, while 0 of the 90 individuals receiving IVERCAR treatment in addition to PPE tested positive for CoVid-19 in the study period. 


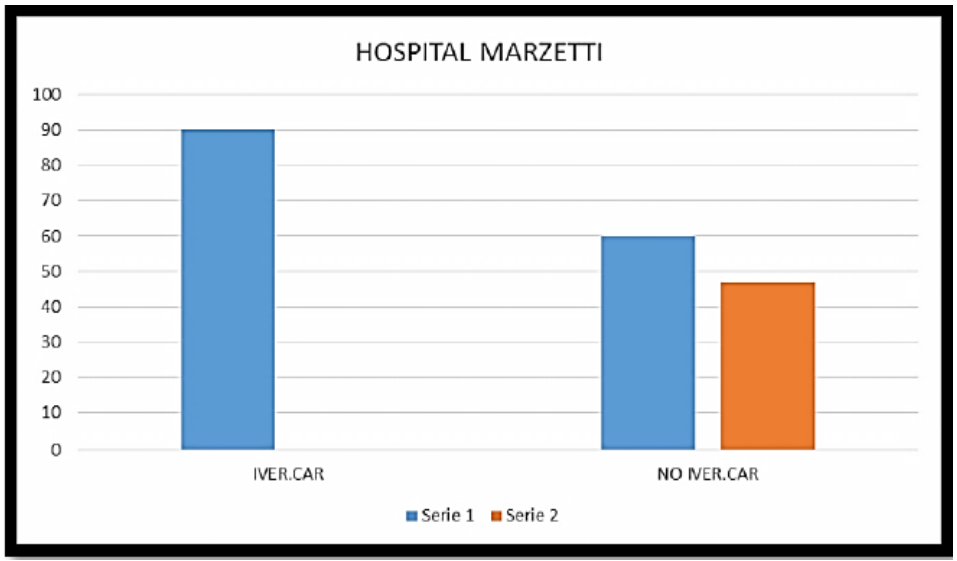

Figure 2: Light Blue: Participant Personnel; Orange: Personnel Infected

\section{Cuenca Alta Hospital - BUENOS AIRES Province:}

Total participating personnel 300; 90 received IVERCAR and 210 used PPE alone. 65 health care personnel (30.9\%) in the PPE alone group returned positive CoVid 19 swabs, while 0 of the 90 individuals receiving IVERCAR treatment in addition to PPE tested positive for CoVid-19 in the study period.

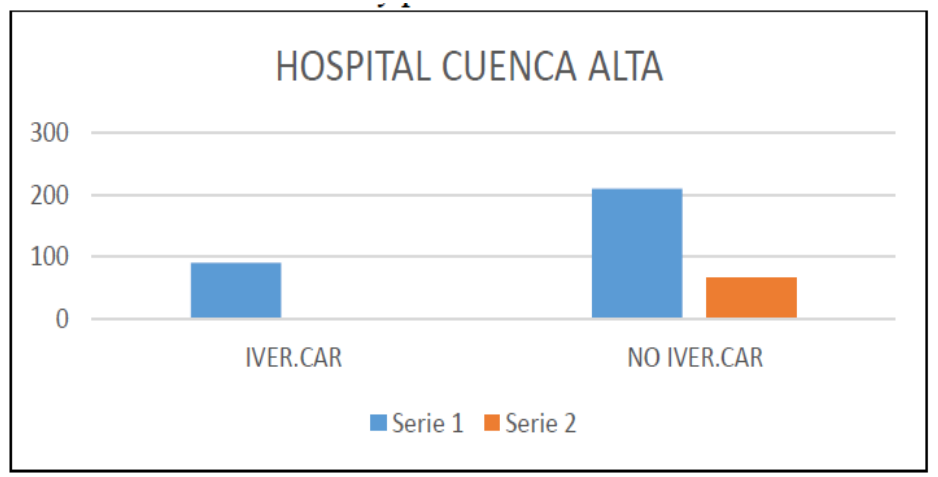

Figure 3: Light Blue: Participant Personnel; Orange: Personnel Infected

\section{Centro Medico Caseros - Buenos Aires City:}

Total participating personnel $15 ; 8$ received IVERCAR and 7 used PPE alone.5 health care personnel $(71 \%)$ in the PPE alone group returned positive CoVid 19 swabs, while 0 of the 8 individuals receiving IVERCAR treatment in addition to PPE tested positive for CoVid-19 in the study period.

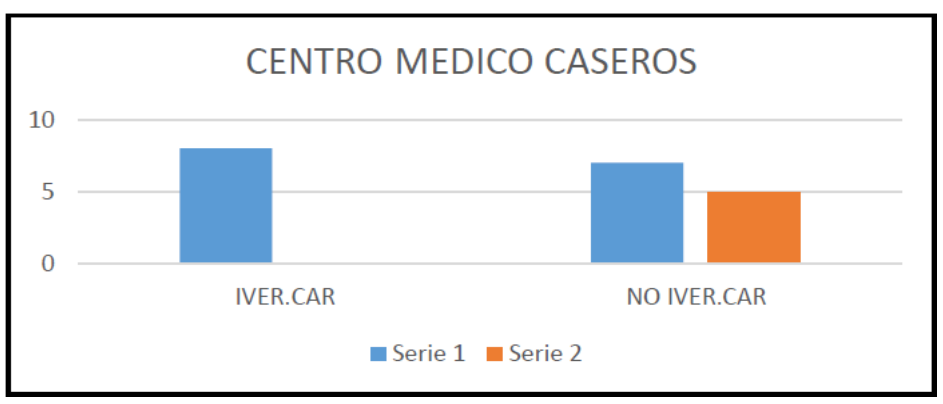

Figure 4: Light Blue: Participant Personnel; Orange: Personnel Infected

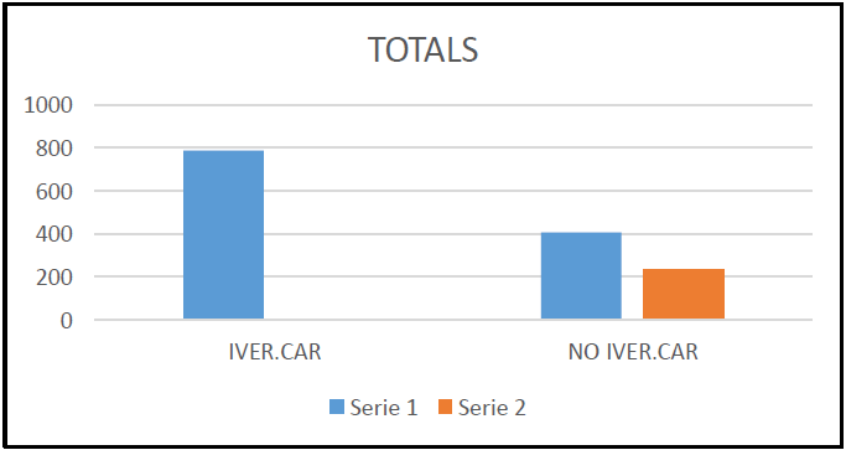

Figure 5: Light Blue: Participant Personnel; Orange: Personnel Infected

\section{Discussion}

In the present two clinical trias, the ethnic and age characteristics, previous health, personal protection measures, performance areas, work hours, and type of patients assisted were the same in each arm.

If we consider the following facts:

1) Drops and sprays are a major source of human-tohuman transmission.

2) The sources mentioned above depend on different sizes of saliva droplets.

3) The contagion comes from symptomatic and asymptomatic patients.

4) The proportion of asymptomatic patients exceeds $30 \%$ of all cases.

5) The concentration of ivermectin and carrageenan is adequate in the nasal mucus and salivary glands.

6) The combined oral solution can offer double protection: on the one hand, it reduces the spread and, on the other hand, it reduces the viral load.

7) Both (ivermectin and carrageenan) are present in the international pharmacopoeia, and their use is widely accepted.

8) Their respective "off label" applications do not involve any risk.

9) Health Personnel are constantly at risk of contagion, thus locking down all their co-workers, and preventing the community from the access to appropriate health care.

We conclude that by using ivermectin in oral solution and carrageenan in nasal spray form, we are providing an inexpensive, safe and effective means to protect people from contagion and serious forms of the disease.

Consent for Publication: Written informed consent was obtained from the patient for the publication. 
Conflicts of Interest: The authors declare no conflict of interest.

\section{References:}

1. Rodríguez MA, Cardona OJ, et al. Clinical, laboratory and imaging features of COVID-19: A systematic review and meta-analysis. Travel Med Infect Dis. 2020;34:101623.

2. Andersen K, Rambaut A, Lipkin I, et al. The proximal origin of SARS-CoV-2. Nat Med. 2020; 26: 450-452.

3. Recalcati S. Cutaneous manifestations in COVID-19: a first perspective. J Eur Acad Dermatol Venereol. 2020;34:e212-e213.

4. Mehta P, McAuley D, Brown M, et al. COVID-19: consider cytokine storm syndromes and immunosuppression. Lancet. 2020;395(10229):1033-1034.

5. Ordoñez Angulo E. Efficacy of ivermectin in the treatment of children parasitized by Strongyloides stercoralis. Biomedica. 2004;24:33-41.

6. Giovannoni F. Rol antiviral intrinseco de PML en la infección con flavivirus.Tesis de doctorado, Universidad de Buenos Aires. Facultad de Ciencias Exactas y Naturales. 2018.

7. Ruiz Esquide Canale MS, Weil M, Turienzo M. Infección por virus Zika y sus manifestaciones cutáneas. Arch Arg Dermatol. 2019.

8. Leon C, Julian DD, Mike GC, et al. The FDA-approved drug ivermectin inhibits the replication of SARS-CoV-2 in vitro. Antiviral Res. 2020;178:104787.

9. Cynthia AG, Christine IF, Arturo GP, et al. Safety, Tolerability, and Pharmacokinetics of Escalating High Doses of Ivermectin in Healthy Adult Subjects. J Clin Pharmacol. 2002;42:1122-33.

10. Guang Chen, Di Wu, Wei Guo, et al. Clinical and immunological features of severe and moderate coronavirus disease 2019. J Clin Invest. 2020;130:26202629.

11. Kelvin Kai-Wang T, Owen Tak-Yin T, Wai-Shing L, et al. Temporal profiles of viral load in posterior oropharyngeal saliva samples and serum antibody responses during infection by SARS-CoV-2: an observational cohort study. Lancet Infect Dis. 2020;20:565-574.

12. Sri Santosh T, Parmar R, Anand H, et al. A Review of Salivary Diagnostics and Its Potential Implication in Detection of Covid-19. Cureus. 2020;12:e7708.

13. Baraka OZ, Mahmoud BM, Marschke CK, et al. Ivermectin distribution in the plasma and tissues of patients infected with Onchocerca volvulus. Eur J Clin Pharmacol. 1996;50:407-410.

14. Edwards G, Dingsdale A, Helsby N, et al. The Relative Systemic Availability of Ivermectin after Administration as capsule, tablet, and Oral Solution. Eur J Clin Pharmacol. 1988;35:681-684.

15. Carvallo, H., Hirsch, R, et al. Ivermectin, aspirin, dexametasone and enoxaparin as treatment for COVID 19. J Am Med Assoc. 200.324.

16. Martin K, Thomas L, Angelika B, et al. Carrageenan nasal spray in virus confirmed common cold: individual patient data analysis of two randomized controlled trials. Multidiscip Respir Med. 2014;9:57.

17. Mitchell VP, William CS, Douglas GR, et al. West Nile Virus Infection in Reindeer (Rangifer Tarandus). J Vet Diagn Invest. 2004;16:219-222.

18. TP de Castro, DPF Duarte, DP Carvalho . Estudo preliminar sobre os efeitos clínicos do tratamento da Febre Chikungunya aguda usando Ivermectina como fármaco antiviral. AMPE. 2017.

19. Hamming I, Timens W, Bulthuis MLC, et al. Tissue distribution of ACE2 protein, the functional receptor for SARS coronavirus. A first step in understanding SARS pathogenesis. J Pathol. 2004; 203:631-637.

20. Xu H, Zhong L, Deng J, et al. High expression of ACE2 receptor of 2019-nCoV on the epithelial cells of oral mucosa. Int J Oral Sci. 2020;12:8.

21. Liu L, Wei Q, Alvarez X, et al. Epithelial cells lining salivary gland ducts are early target cells of severe acute respiratory syndrome coronavirus infection in the upper respiratory tracts of Rhesus macaques. J Virol. 2011;85:4025-4030.

22. Wang WK, Chen SY, Liu IJ, et al. Detection of SARS associated coronavirus in throat wash and saliva in early diagnosis. Emerg Infect Dis. 2004;10:1213-1219.

23. Chen L, Jiajia Z, Jinfeng $P$, et al. Detection of 2019-nCoV in Saliva and Characterization of Oral Symptoms in COVID-19 Patients. Cell Prolif. . 2020;00:e12923.

24. Lagerlo F, Dawes C. The volume of saliva in the mouth before and after swallowing. J Dent Res. 1984;63:618-621.

25. Eduardo L. Ceccotti: El COVID-19. La Saliva y la Mucosa Lingual. Población y Profesionales en Riesgo. ADMIN, MAYO 5, 2020. Academia Nacional de Odontología Argentina.2020.

26. Emma AH, Ruth F, Susan MC, et al. Virucidal Activity of Polysaccharide Extracts from Four Algal Species against Herpes Simplex Virus. Antiviral Res. 2009;83:282-289. 